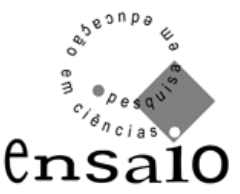

\title{
EPISTEMOLOGIA, ÉTICA E POLÍTICA NA FORMAÇÃO DE PROFESSORES DE CIÊNCIAS
}

\author{
EPISTEMOLOGY, ETHICAL AND POLITICAL IN THE PREPARATION \\ OF SCIENCE TEACHERS
}

\author{
Paulo Sérgio Araújo da Silva* \\ Sílvia Nogueira Chaves ${ }^{* *}$
}

\begin{abstract}
Resumo
Este artigo relata investigação desenvolvida em processo de formação continuada de professores de ciências (das disciplinas Química, Biologia, Física e Ciências da Educação Básica) no âmbito de um curso de especialização de uma universidade pública. Tal investigação consiste em pesquisa narrativa por meio da qual se busca compreender relações entre reflexão epistemológica e formação docente. Procurou-se, particularmente, investigar que tipos de reflexões os sujeitos-professores constroem a partir da introdução de discussões relativas ao processo de produção, validação e apropriação social do conhecimento científico e as relações que estabelecem com suas histórias de atuação e formação pessoal e profissional. A análise do material empírico produzido sinaliza que dentre os aspectos nos quais o debate epistemológico estimulou reflexões, está a dimensão ético-política da ciência. Tais reflexões levaram os professores a reverem seus processos formativos, estabelecendo relações entre produção científica e critérios sociais de validação da ciência, como também a submeterem a análise de suas próprias práticas educativas a esses critérios.
\end{abstract}

Palavras-chave: Formação de professores de ciências. Epistemologia da ciência. Investigação narrativa. Ética e política na ciência e no ensino de ciências.

\begin{abstract}
This work is about the investigation developed during the process of continual formation of science teachers (from the subjects of Chemistry, Biology, Physics and Primary School's Sciences) in a public University. This work consists in a research in wich we try to understand the relations between epistemological refletion and teacher formation. We investigate, particularly, what kind of reflections the science teachers have built from the discussions about the process of production and social appropriation of science and the relations that they establish with the stories of their professional forming and performance. The analysis of this material pointed that

\footnotetext{
* Pesquisador do Núcleo de Educação Científica, Ambiental e Práticas Sociais (Necaps/UEPA) e Professor Assistente I do Departamento de Ciências Naturais da Universidade Estadual do Pará. Desenvolvemos a presente pesquisa no âmbito do NPADC/UFPA- Núcleo de Apoio ao Desenvolvimento Científico da Universidade Federal do Pará no Programa de Pós-Graduação em Educação em Ciências e Matemáticas, no qual obteve o título de Mestre em 2007. paulo_a_s@yahoo.com.br.

** Professora do Programa de Pós-Graduação em Educação em Ciências e Matemáticas do NPADC/UFPA. Doutora em Educação.
} 


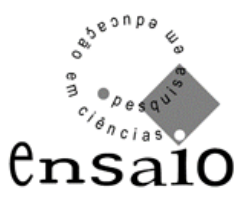

among all the aspects in wich the epistemological debate simulated reflections the ethical-political dimension of science is always present. Such reflections led them to review their formative processes establishing relations between scientific production and social criterions of validation of science, as well as they accepted to analyse their own educative practices to these criterions.

Keywords: Preparation of science teachers. Epistemology of science. Narrative research. Ethical and political in science and science Teaching.

\section{A DISCUSSÃO EPISTEMOLÓGICA NA FORMAÇÃO DOCENTE}

Nos últimos anos discussões sobre a importância da reflexão epistemológica na formação docente, vêm ganhando cada vez mais espaço na literatura da área de Educação em Ciências (MALDANER, 1997, 2000b; COLOMBO et al., 2004; CACHAPUZ et al., 2005; CHAVES, 2005).

Nessa perspectiva, se tem buscado discutir e problematizar as diferentes concepções de ciência que atravessam a história da humanidade e seus desdobramentos na constituição e orientação das práticas educativas, particularmente aquelas relativas às disciplinas da área de ciências (química, física e biologia).

Isso porque, parte-se do pressuposto de que muitas posturas e condutas assumidas no campo da Educação em Ciências encontram-se alicerçadas em concepções racionalistas, empírico-indutivistas próprias do pensamento moderno que legitimou uma única forma de saber em detrimento de outras tantas culturalmente válidas. Entende-se, ainda, que o processo de adesão por parte dos professores a essa concepção epistemológica, constrói-se de maneira tácita, irrefletida e decorre, entre outras coisas, da imersão e vivência de modelos, práticas e sintaxe próprias do fazer científico, difundidos no interior dos cursos de formação nos quais se constituíram profissionalmente.

As principais críticas e preocupações que advêm do cultivo desse tipo de concepção estão na postura excludente e hierarquizada que se assume diante de outras formas de saberes culturalmente constituídos. Tais posturas, usualmente, têm produzido como desdobramentos sociais a intolerância e o preconceito. No âmbito pedagógico os conteúdos escolares são apresentados de forma fechada, impenetrável a 


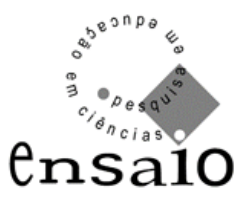

questionamentos e, nessa perspectiva, passam a ter valor absoluto e não relativo ao que trazem de contribuição para ampliar, acrescentar a outras formas de compreensão do mundo.

Tomando por base essas compreensões e pressupostos empreendemos uma pesquisa, na qual investigamos a natureza das reflexões que emergem da inserção de discussões epistemológicas na formação de professores de ciências, bem como as maneiras como essas reflexões afetam a forma com que docentes compreendem e lidam com o conhecimento que ensinam em suas práticas pedagógicas.

Para tanto, elegemos como lócus de pesquisa um processo de formação continuada de professores de ciências (das disciplinas; Química, Biologia, Física e Ciências da Educação Básica) realizado por meio de um curso de Especialização em Ensino de Ciências, desenvolvido em uma universidade pública. Do conjunto das disciplinas ofertadas no curso acompanhamos a primeira disciplina ${ }^{1}$, por ser nesta que temáticas diretamente voltadas para a dimensão epistemológica da ciência seria tratadas. Estiveram envolvidos naquele processo formativo; a formadora - Graduada em Ciências Biológicas doutora em Educação na área de Ensino de Ciências e os professores participantes - Graduados na área de ciências naturais, ou seja, atuando profissionalmente no ensino das disciplinas Química, Biologia, Física e Ciências no ensino fundamental.

Ao acompanharmos tal processo nosso objetivo foi compreender relações entre reflexão epistemológica e formação docente. Interessou-nos, particularmente, investigar que tipos de reflexões os sujeitos-professores construíram a partir da introdução de discussões relativas à produção, validação e apropriação social do conhecimento científico e as relações que estabeleceram com suas histórias de atuação e formação pessoal e profissional.

Com essa intenção solicitamos que os professores participantes produzissem narrativas memorialistas, nas quais relatassem aspectos sobre os quais havia incidido as questões epistemológicas postas em debate durante os, aproximadamente, dois meses em que durou a disciplina acompanhada nesta pesquisa. Além dos registros memorialistas, produzidos ao final desta, foram utilizados, também, como fonte de

\footnotetext{
${ }^{1}$ A organização curricular do curso foi feita em 4 módulos de disciplinas. A disciplina em questão foi a primeira trabalhada no primeiro módulo daquela Especialização.
} 


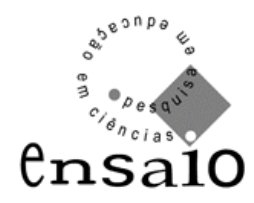

investigação transcrições das aulas da disciplina registradas em áudio e anotações de campo que produzimos durante as aulas.

A análise do conjunto de materiais produzidos sinaliza que a ação recursiva da memória, estimulada a partir de discussões epistemológicas, no presente, potencializou as reflexões docentes em quatro dimensões principais: Ético-política, Curricular, Metodológica e Afetiva.

Atendendo o limite estabelecido para esse texto, para efeito de análise traremos para discussão as reflexões que incidiram somente sobre a dimensão ético-política do fazer docente.

Os depoimentos aqui agrupados, referem-se à reflexão dos professores que incidem sobre a produção/fabricação da ciência, implicações éticas e políticas tanto na organização do trabalho científico quanto na prática educativa dos professores de ciências, as concepções de ciência dogmática neutra e autônoma, bem como a inserção de tais concepções na cultura escolar.

A palavra ética é aqui utilizada como acepção daquilo que tem um limite numa questão moral, até onde se pode ir sem incorrer num processo desumanização e alienação dos sujeitos em suas dimensões culturais, sociais, econômicas, por meio de uma atividade, seja ela a atividade docente ou científica, por exemplo. Já o político se refere às decisões tomadas no âmbito de uma atividade, e aos elementos de decisão que alicerçam tais atividades de ordem econômica, social, cultural etc.

Vale destacar que nossa investigação incidiu privilegiadamente sobre a dimensão ideacional, conceitual e não propriamente sobre as condutas profissionais desencadeadas pelas discussões epistemológicas travadas durante o processo formativo. Isso porque, compreendemos que a dimensão atitudinal não depende exclusivamente de mudanças conceituais, há todo um contexto com o qual se precisa negociar para implementar novas práticas e posturas pedagógicas.

Assim, é sobre a repercussão das discussões epistemológicas, em termos reflexivos e conceituais que apresentamos e analisamos, a seguir, do material empírico produzido nessa investigação. 


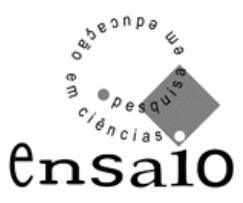

\section{QUANDO O EPISTEMOLÓGICO FAZ PENSAR NO ÉTICO-POLÍTICO}

Não foram raros os questionamentos acerca da visão de ciência dogmática e neutra. Nessa direção, incidiram várias discussões entre os professores envolvidos na disciplina, como pode ser percebido nos registros de Elton, Mara e Maurício²: no qual evocam algumas situações e discussões desenvolvidas durante as aulas.

Houve uma vez a exibição de um filme sobre a AIDS: "E a vida continua..." Nele, pude perceber que a ciência não é só aquela imagem de ciência de laboratório, que descobre coisas para ajudar nas dificuldades, às quais o homem pode ser vítima ou proporcionar melhores condições a ele. Ela também tem seu lado político, capitalista, burocrático, e até mesmo, mesquinho (Elton: memorial, destaques nosso).

Essas discussões e reflexões [no curso de especialização] me ajudaram a perceber que: cabe a nós, professores, mostrar que a ciência é uma atividade humana, feita coletivamente, não está alheia a fatos históricos, sociais e políticos, é feita por homens (mulheres) que têm por trás de suas ações, interesses nem sempre éticos. (Mara: memorial)

A disciplina, também provocou em mim, a construção de novos olhares no que se refere aos bastidores da Ciência. Devo dizer, que a minha visão limitada sobre a ciência não me permitia ver que ela (a Ciência) é impregnada das manifestações pessoais dos homens e mulheres que fazem a Ciência. Essas manifestações envolvem interesses comerciais e políticos mais diversos, até mesmos obscuros. (Maurício: memorial)

As três reflexões apresentadas questionam a visão dogmática de ciência neutra, isenta de valores. Para o professor Elton, tais reflexões estão conectadas à lembranças particularmente situadas em um momento de aula no curso de especialização, em que foi exibido e problematizado o filme E a Vida Continua ${ }^{3}$. Ao mencionar a exibição do filme, Elton evoca outro lado da ciência que ele passa a perceber: o seu lado político, capitalista, burocrático e, até mesmo, mesquinho. Ou seja, ele percebe a semelhança, de Mara, que a ciência é uma atividade humana que tem (...) interesses, nem sempre éticos.

\footnotetext{
${ }^{2}$ A fim de resguardar a identidade dos sujeitos dessa pesquisa, todos os nomes utilizados nesse texto são pseudônimos.

${ }^{3}$ Filme produzido pela $\mathrm{HBO}$ para a televisão baseado em episódios recentes da pesquisa científica sobre a AIDS.
} 


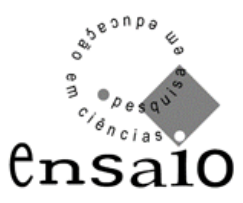

Esse reconhecimento traz implicações na formação de professores de ciências, como fica sinalizado nas convicções de Mara. Ela chama, pois, para si e para os demais professores, a responsabilidade de desmitificar a ciência, de mostrar entre outras coisas, que há aspectos éticos envolvidos no fazer científico. A compreensão dessa responsabilidade docente, em desmitificar a ciência, se forja ao refletirem a respeito do desenvolvimento da ciência e das suas implicações no mundo em que vivem, sobretudo em relação ao constante atentado à vida, ao desrespeito cada vez mais à vida, como foi destacado no memorial de Diogo, pois essas discussões o levaram a refletir sobre o papel do professor no mundo atual.

Estas experiências [na disciplina] me deixaram com algumas impressões. Elas me fizeram refletir sobre o papel do professor no mundo atual.Vivemos uma época marcada por um desenvolvimento acelerado da ciência. Mas também uma época marcada por uma crise de valores humanos que tende a desrespeitar cada vez mais a vida. Senti que isso ficou subjacente nas aulas da disciplina. Ficou claro pra mim que, como professor de ciências, tenho um papel a desempenhar e que este papel deve iniciar em minha prática de ensino, que devo apresentar a ciência como atividade humana sujeita a falhas, acertos e limitações, pois a ciência não se desenvolve num espaço social e cultural vazio, mas condicionada a fatores externos. (Diogo, memorial, destaques nosso).

Os professores participantes, ao contemplarem essas compreensões do papel do professor em apresentar a ciência como atividade humana sujeitas a falhas, acertos e limitações, se desenvolvendo num espaço social e cultural nenhum pouco enclausurado, mas condicionada a fatores externos, estão a compreender que, "as idéias de autonomia da ciência e do desinteresse do conhecimento cientifico que durante muito tempo constituíram a ideologia espontânea dos cientistas, colapsaram perante o fenômeno global de industrialização da ciência...” (SANTOS, 1988, p.59).

Estão, também, a assinalar no âmbito de suas reflexões, um importante desafio na sua prática educativa; o de combater a concepção de ciência neutra autônoma e desvinculada do espaço social e cultural em que todos os seres vivos habitam. Desse modo, projetam no âmbito de suas práticas educativas a responsabilidade de apresentar a ciência - a razão científica - como limitada e com suas conseqüências éticas e políticas. Conseqüências essas que foram sendo ignoradas 


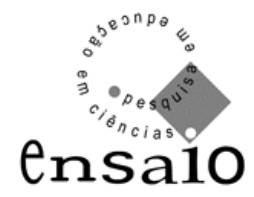

no desenvolvimento da ciência moderna. Isso porque, "na modernidade, a razão se torna autocompreensiva (...). Em sua auto-afirmação soberana a razão ignora seus limites e sua necessária ancoragem em critérios éticos-políticos" (MARQUES, 2002, p.84).

Reflexões sobre os limites da apresentação de uma ciência neutra, autônoma, em situações de aula, também podem ser depreendidas quando a professora Luciana põe em evidência aspectos éticos da pesquisa científica, neste diálogo, travado com a formadora ${ }^{4}$ durante uma aula:

- Agora me recordo que saiu um artigo da Super-Interessante desse mês, sobre uma pesquisa nos Estados Unidos. Eles usaram uma população de negros, com uma doença na década de 70. (Luciana).

- Eu vi o filme. (F)

- Fiquei chocada. E essas pessoas da pesquisa, não podiam procurar os hospitais públicos, clínicas particulares, que eles não iam ser atendidos, porque eles tinham que ficar com a doença para que eles fossem pesquisados, com os seus sintomas, tanto que hoje só tem uma pessoa daquelas que está viva. (Luciana)

- Estou tentando me lembrar do nome do filme, que conta esse episódio, quem tiver assistido, me ajude. Bill Clinton teve que pedir desculpas publicamente à comunidade negra porque eles fizeram isso. (F)

- Foi esse, foi esse...foi esse. (Luciana)

- Quando se descobriu os antibióticos no período da guerra da secessão dos Estados Unidos, quando a sífilis começou a proliferar entre a população, eles selecionaram um grupo de negros para ser o grupo controle (das pesquisas). Eles estavam testando os antibióticos para serem utilizados pelos brancos. Davam para os brancos antibióticos para sífilis, e não davam para os negros. (F)

- E eles não sabiam que tinham a doença. (Luciana)

- Eles não sabiam que tinham a doença. Tem um filme! Alguém viu este filme? O filme é da década de 90 . O filme não é antigo. O Clinton pediu desculpa publicamente. Não era ele o governante da época (em que foi feita a experimentação com os negros), mas ele pediu, como

\footnotetext{
${ }^{4}$ Ao longo do texto, a professora que ministrou a disciplina Ciência e Ensino será designada como formadora e aparecerá nas transcrições representada pela letra F.
} 


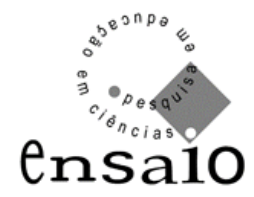

nação, desculpa à comunidade negra e isso virou um documentário. Então, essa ciência está toda misturada com a sociedade.Temos que começar a contar para os nossos alunos que isso existe e que ela é assim, e trabalhar isso na formar de apresentar os conteúdos. Não é falando como eu estou falando agora, numa aula de Ciência e Ensino, é no meio dos conteúdos que isso vai ficando claro, vai se revelando. $(\mathrm{F})$

Problematizações como as que ocorreram nesse episódio, foram decisivas para que os professores encarassem a ciência como uma atividade humana, coletiva, historicamente situada, um empreendimento constituído social e politicamente e para construírem a compreensão que essa ciência está toda misturada com a sociedade, faz parte dela e, por isso, articula ações e interesses nem sempre éticos. Assim, um importante papel do professor é começar a revelar aos alunos as relações existentes entre ciência e sociedade, associada à forma de apresentar os conteúdos. Essa compreensão parece ter sido alcançada por Diogo: - Ficou claro pra mim que, como professor de ciências tenho um papel a desempenhar e que este papel deve iniciar em minha prática de ensino.

Nesse aspecto, parece que os professores estão muito próximos de assumirem que "todo conhecimento científico-natural é científico-social" (SANTOS, 1988, p.60) e, na mesma medida, que é inconcebível, adotada essa perspectiva, uma formação de professores para o ensino de ciências que trate dos impactos da ciência e da tecnologia no mundo "natural" desvinculados da dimensão social, como se esses impactos fossem independentes das ações e opções humanas, da sociedade e de seus valores.

Recordamos que essa tese de Santos (1988) foi implicitamente assumida nas discussões dos professores participantes. Ela nos parece autêntica no sentido da discussão dos impactos da ciência e da tecnologia no mundo, para situar as responsabilidades desses impactos nos seres humanos, e não mais estritamente nos fenômenos (as coisas), na natureza. Trata-se de não negar os valores no âmago da ciência, como se tem feito sob o pretexto da imparcialidade, autonomia e neutralidade, como valores subjacentes às práticas cientificas (LACEY, 2004). A reposição desses valores na constituição da ciência destacada pela formadora, foi associada à discussão do ensino e se traduziu nas reflexões formuladas pelos professores participantes. 


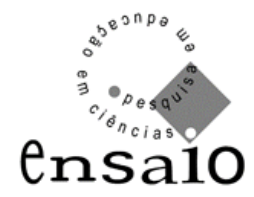

Aprendi, que quando fazemos Educação buscamos fazer transformações (...). Hoje, nossas gerações de crianças e jovens, vivem em um mundo totalmente globalizado, com visões tecnicistas e assépticas de ciência, dificultando, com isso, um ensino mais humano, no qual o objetivo principal seria a formação do cidadão crítico e consciente da sua cidadania. Como professor, tenho o dever de enfrentar este desafio do século XXI, o de buscar romper as barreiras que dificultam a formação de cidadãos críticos e perfeitamente engajados com a sua cidadania e com o mundo em que vivemos (Hugo: memorial).

A reflexão de Hugo está relacionada a determinados momentos de discussão em aula, como um, em particular, em que foi debatido o texto Buscando um ensino menos apolítico, de Chassot (2003, p.101). Nele, o autor relata: “Quantas vezes ouvi, e até disse: “somos professores de química e a nossa responsabilidade é ensinar o conhecimento químico preferentemente invocando a neutralidade do conhecimento" (destaques no original).

Tal discussão ganhou "corpo" durante as aulas nas quais a idéia de Chassot, de que não existe ensino solto, isento de qualquer influência, foram debatidas.

- Eu me recordo de um colega, quando eu perguntava qualquer coisa a respeito da situação do país, ele dizia: "não me pergunte!", "eu sou apolítico", e aí ele foi enchendo o bolso de dinheiro e tudo mais, ficou rico na vida até hoje. $\mathrm{Na}$ verdade, ele não estava sendo apolítico, ele estava tomando uma posição política. Acho que a questão do ensino é a mesma coisa. Eu acho que, não se pode ter um ensino solto, isento de qualquer influência da situação daquela comunidade ou de um país de um modo geral. Não pode haver um ensino dissociado da realidade que os estudantes, os professores estão. (José)

- Existe ensino apolítico? É essa a discussão. Existe alguma forma de ensinar, educar apolítica? Não existe isso! Não existe uma forma de ensinar apolítica. Existe uma forma de ensinar, de educar que é falsamente neutra. Essa forma acredita que é possível dizer "eu não quero me envolver com interesses de nenhum grupo", mas é pseudo, pois não tem como você ser omisso em determinadas discussões. Porque o fato de você não enfocar determinados aspectos, significa uma opção política, é opção; ser político é tomar uma decisão. (...) Acatar, também é uma atitude política, você aceitar determinado tipo de ação social, de determinismo econômico, é uma ação política. Não existe nada apolítico, nós não somos apolíticos, qualquer atitude que a gente tome, mesmo a de ficar parado é uma atitude política.(F)

- Você pode ser apartidário [mas não apolítico]. (Hugo) 


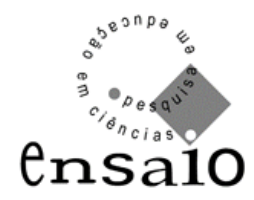

- Exatamente. (F)

É na contramão desse ensino, que se diz: solto isento de qualquer influência que Chassot (2003) argumenta que o desenvolvimento de uma ciência, que tem tanto seu lado benéfico, como maléfico, precisa estar associado ao ensino de Ciências. Para ele, envolver essa dimensão no ser professor implica admitir que temos escolas aparentemente impregnadas por dois modelos:

Uma, onde se oferece um ensino que pode proporcionar aos adquiridores que continuem cada vez mais dominados e mais domesticados para aceitarem as relações de desigualdade, a outra é a que, através da Educação alunos e alunas tornem-se capazes de compreender a realidade em que estão inseridos e então modificá-la na busca de transformações (p.104).

É por isso que a reflexão de Hugo vai ao encontro dessa segunda perspectiva de formação — quando fazemos Educação buscamos fazer transformações (...). Como professor tenho o dever de enfrentar este desafio do século XXI, o de buscar romper barreiras que dificultam a formação de cidadãos críticos e perfeitamente engajados $e$ com o mundo em que vivemos (memorial).

A perspectiva de educar pela Ciência para gerar transformações, de se praticar um ensino político, fez o professor Rafael entrar em parafuso ao refletir sobre a apresentação de uma ciência (química) pura.

- Eu percebi que sempre trabalhei na iniciação científica, na fitoquímica e nunca me liguei muito na área de educação. Aí, nesta área da educação, eu estou um ano e meio dando certo e, quando eu me deparei com esse tipo de questão do ensino [político] com outras bibliografias questionadoras, comecei a questionar as minhas aulas e, comecei a entrar em parafuso. Eu tenho um terceiro ano (do Ensino Médio) a noite que eu estava ensinando a química pura para eles e... (Rafael)

- Estavas formando químicos? (F)

- Isso, e o quê que aconteceu! Eu fiquei me questionado, fiquei desmotivado nas aulas. Por que estou ensinado isso? Para que vai servir esse ensino para esse povo? Fiz essa retrospectiva quando me deparei com esse tema hoje. Eu estava pensando, com esse pensamento bem de químico mesmo, a gente não quer saber por que esse ensino é importante. Está certo que a gente não vai resolver os problemas sociais que são imensos dentro e fora da escola, mas fiquei pensado nisso, em que esse ensino pode servir para transformar o mundo para melhor? (Rafael) 


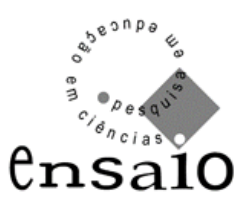

Ao refletir sobre o caráter político do ensino de ciências, o professor Rafael repensa a implicação de uma concepção de ciência pura, ciência neutra para o seu ensino, pois, como disse, quando a gente está com esse pensamento bem de químico mesmo, a gente não quer saber, por que esse ensino é importante. Os principais questionamentos que o professor passou a fazer foram: Por que estou ensinado isso? Para que vai servir esse ensino? Essas indagações parecem encontrar guarida nas proposições de Cachapuz, Praia e Jorge (2004, p.336) quando asseguram que:

\begin{abstract}
(...) um tal debate sobre o estatuto epistemológico da Educação em Ciência só tem verdadeiramente sentido educacional se estiver articulado com a questão da justificação social da Educação em Ciência, questão esta com profundas conseqüências. A questão nuclear passa por termos de rever respostas sobre o para quê e não só sobre o o quê (questão ligada aos currículos) e o como (questão ligada às estratégias de trabalho) (destaques no original)
\end{abstract}

Tais discussões que pensam e propõem a educação como transformação pressupõe um processo de desalienação da ciência como conhecimento dogmático, inquestionável. O professor Rafael deixa explícito em seu memorial o quanto essa desalienação lhe "perturbou".

Entrei dia 18/01/04, no curso de especialização no ensino de ciências. Recordo que a primeira aula que participei, era justamente acerca do ensino de ciências. A citação de Crodowaldo Pavan, sobre a visão de ciência como conhecimento confiável e os demais conhecimentos suspeitos. Esta citação se enquadrou na minha maneira de pensar. Após a discussão, percebi que estava enganado, que não podemos delegar à ciência o papel de decidir o que é bom para nós. A partir daí, fui apresentado a uma nova concepção de ciência: "uma forma de compreender o mundo mutável, fruto do trabalho coletivo, "contaminada" pelas paixões humanas, parcial, socialmente hegemônico, mas não necessariamente melhor. Acho que depois desta aula, eliminei parte do dogmatismo que estava dentro de mim em relação à ciência. Digo em parte do dogmatismo, porque é difícil mudar a minha maneira de pensar de uma ora para outra, tenho uma carga de tradicionalista muito grande dentro de mim. (memorial)

Rafael refere-se a uma situação de aula, em que a formadora questionou a concepção hierarquizada de ciência como a única forma de conhecimento válido, ou ainda como a melhor maneira de conhecer o mundo. Situação presente nos trechos de diálogos que seguem, do quarto encontro com os professores participantes. 


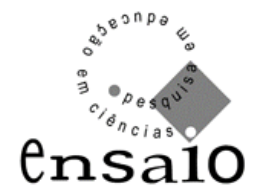

- Observe "essa frase aí", depois eu vou falar da propaganda que me incomoda na televisão. "Essa frase aí" é do Crodowaldo Pavan, vocês sabem quem é Crodowaldo Pavan? Ele foi durante muitos anos presidente da SBPC, e ele é um geneticista famoso, importante no País, importante na comunidade científica. Ele vai reforçar essa visão de ciência como conhecimento melhor dizendo o que ele diz aí, numa revista de divulgação científica a Super-Interessante e, diz assim "é importante que a população brasileira acredite no que nós, os cientistas, estamos dizendo, mesmo que a princípio, não entendam direito os princípios das descobertas mais complexas". (F)

- Assim também não dá! (Hugo)

- Ou seja, confie em nós que a gente sabe o que estamos fazendo para vocês. Quando vi a frase do Crodowaldo Pavan, lembrei de uma propaganda de uma empresa do ramo da telofonia fixa sobre a fibra ótica, vocês lembram dessa propaganda? (F)

- Lembramos. (Várias vozes)

- Ela dizia mais ou menos assim: a fibra ótica é uma coisa muito boa, fala Maria, Aninha com o Joazinho que tá lá não sei aonde, que tá lá ...e liga no dia das mães, no dia dos pais, no dia... e tentaram explicar o que é fibra ótica lá pelo meio da propaganda. E no final ele [o locutor] diz assim: "você não entendeu o que é fibra ótica? Mas se você não entendeu não tem problema, basta você usar". Voltando para aquela pergunta que teu aluno te fez, para que a gente ensina ciência, se eu vou ser advogado, engenheiro, mecânico, puxador de carroça? É para eu poder/saber me posicionar diante das coisas que são colocadas no mundo. O mundo está mergulhado nesse contexto científico e eu preciso dizer se eu quero isso, ou não quero aquilo, e para eu saber não tenho que confiar nos outros, eu tenho que entender sim, tenho que entender o que é fibra ótica, entender para dizer "olha! Eu não quero essa tecnologia porque se essa tecnologia me traz conforto, mas ela pode trazer prejuízo ambientais para mim e para as gerações futuras, mas não conseguimos fazer isso. Por que? Porque a escola está afastada dessa discussão, ensinamos fórmulas, definições, ensinamos um monte de coisas e essas coisas importantes ficam fora da escola. Quando chega um cidadão e me pergunta se eu quero ou não comer transgênico, eu não sei. Por quê? Porque não domino a linguagem científica, porque não compreendi a linguagem da ciência. Lembra que o Chassot disse que a ciência é uma linguagem, a ciência, é uma linguagem, a gente precisa ser alfabetizado nela. É como uma pessoa ignorante numa determinada língua e você diz assim "assina esse documento aqui" a pessoa não sabe ler e assina sem entender. É isso que temos feito socialmente, assinado coisas pela ciência sem entender; dado procuração em branco, porque não entendemos, não nos permitiram que fosse feita essa compreensão...nem para nós professores da área. Às vezes, nós, 


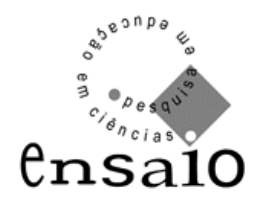

professores da área, também não entendemos coisas de tão hermética que está a linguagem científica. É para isso que ensinamos ciência na escola; para formar esse cidadão que possa dizer: eu quero ou não quero essa nova tecnologia, porque o conforto que ela me traz não supera os problemas socais e ambientais que vai trazer junto com ela. $(F)$

- O pior é isso! (José)

- Não sabemos, porque a nossa ciência, o ensino de ciência está asséptico. (F)

- A ciência está a serviço de um capital. (Leandro)

- Perfeito, a ciência está a serviço de um grupo social. E nós precisamos deixar isso claro na sala de aula, porque a ciência que temos apresentado é uma ciência neutra. (F)

A recordação pelo professor Rafael da problemática da ciência como conhecimento confiável, concebida como verdade dogmática assinala que essa concepção deixa o poder da tomada de decisão dependente da ciência ou do que a ciência legitima como bom e/ou ruim. Dessa maneira, as intencionalidades políticas ou as tomadas de decisões são assumidas tanto por professores e alunos quase sempre à espera do respaldo do conhecimento científico, muitas vezes de maneira praticamente não refletidas ou assumidas de forma pouco consciente, alienada - Após a discussão percebi (...) não podemos delegar à ciência o papel de decidir o que é bom para nós (Rafael).

As implicações desse tipo de formação, consciente do limites das soluções baseadas em argumentos científicos e nos produtos da ciência, em vários campos da atividade humana, medicina, telecomunicações, dente outros, está no cerne de uma formação docente politicamente comprometida com o cidadão. Aquele que precisa assumir posição ou decidir sobre os rumos da ciência e da tecnologia em uma ação social direcionada, como disse a formadora $-E$ eu preciso dizer se eu quero isso, ou não quero aquilo, mas isso vai se tornando possível dominado a linguagem que é dominante, que é predominante, linguagem da ciência. Então, há necessidade de alfabetização nessa linguagem. Portanto, como alunos e como professores, é pretendido que não fiquemos à margem dessa linguagem da ciência. Isso não significa dizer que conhecer o que há de novo nela é que vai nos atualizar em termos 


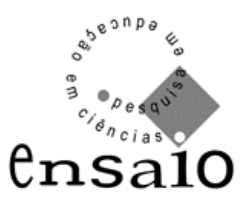

lingüísticos, mas sim compreender a estrutura e a lógica de relações que está dentro da ciência.

Finalmente, ao recordar refletindo sobre aquela situação de aula sobre a visão de ciência como conhecimento confiável e os demais conhecimentos suspeitos, o professor Rafael destaca: -Acho que depois dessa aula eliminei parte do dogmatismo que estava dentro de mim em relação à ciência. Essa eliminação parcial revela que estamos necessitados de fazer as mesmas perguntas de Rousseau, retomadas nas palavras de Santos (1998, p.47):

Estamos de novo regressados à necessidade de perguntar pelas relações entre ciência e a virtude, pelo valor do conhecimento dito ordinário ou vulgar que nós, sujeitos individuais ou coletivos, criamos e usamos para dar sentido às nossas práticas e que a ciência teima em considerar irrelevante, ilusório e falso; e temos finalmente de perguntar pelo papel de todo conhecimento científico acumulado no enriquecimento ou no empobrecimento prático das nossas vidas, ou seja, pelo contributo positivo ou negativo da ciência para a nossa felicidade.

É a respeito da necessidade do regresso desse tipo de questionamento da ciência e os demais conhecimentos, que a professora Ana comenta em suas memórias.

Uma de minhas reações imediatas quando li alguns textos propostos e após as discussões coletivas, foi a de perceber que sempre me referi à Ciência como verdade dogmática, a única forma adequada de conhecer o mundo e a melhor que eu tenho para ensinar. A partir desses momentos, compreendi algo diferente. Poderia e posso questioná-la, manifestar incertezas e utilizar certos termos como provavelmente, não apenas exclusivamente, piamente etc. Confiava de uma maneira até ingênua, somente nos cientistas e dava total credibilidade para as suas descobertas científicas. Com essa atitude, não dava importância a outras formas de conhecimento, outros modos de pensar, os quais, são também indispensáveis para me ajudar a compreender o processo de (trans)formação como algo inacabado, sempre em busca de novos desafios. (memorial)

É explícita nas memórias de Ana a tomada de consciência da visão de ciência que se constitui como a única forma adequada de conhecer o mundo e o melhor que essa professora tem para ensinar. Hoje, percebemos que ao surgirem problematizações acerca da hierarquização da ciência colocou-se implicitamente em destaque que "a supervalorização da ciência gerou o mito da salvação da humanidade, ao considerar que todos os problemas humanos podem ser resolvidos cientificamente" 


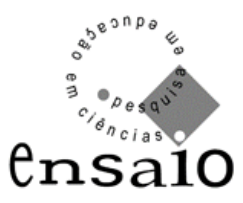

(SANTOS \& MORTIMER, 2002, p.1). Daí porque Chaves (2005, p.3-4) critica a hierarquização "do conhecimento científico frente a outras formas de produções culturais". À semelhança da investigação dessa autora, em nossa pesquisa, observamos que os professores:

ao problematizarem a visão dogmática de ciência neutra, isenta de valores e ao assumirem-na como obra humana, feita por homens e mulheres, misturada com as concepções de mundo que cada um traz, os professores passam a considerar legítimas outras formas de conhecimento, impondo-se dever de não permanecerem cegos a outros saberes. (grifos no original)

Entendido que a ciência não tem todas as respostas para nossa vida, a professora Júlia destaca que é preciso ter uma visão global do todo, mas o todo não é só a teoria cientifica. Ela se mostra a favor de sustentar debates e de considerar outras formas de conhecimento.

Entendo que devemos ter além do conhecimento específico da disciplina, uma visão global do todo, capaz de promover, argumentar e sustentar debates no campo da ciência e tecnologia de forma contextualizada e interdisciplinar. Assim, quando nos posicionamos diante de uma determinada situação, devemos ter o cuidado com a postura do tipo "certo" ou errado ou daquele que tem explicações para todos os problemas levantados, ou seja, a idéia de "verdade". Penso que é válido reforçarmos outras formas de conhecimento, que, por mais que não seja aquela que eu comungue, nem por isso tem sua importância diminuída e desrespeitada (memorial).

Em outras palavras, é uma questão de ensino político problematizar relações valorativas sobre a ciência e tecnologia e a sociedade, mantendo essas relações cada vez mais incorporadas ao conteúdo de ensino de ciências, em contraposição ao modelo de ensino puramente conceitual. Mas esse questionamento não pode mais estar rotulado pelo "certo" ou pelo “errado". É por esse caminho que Júlia entende ter coerência uma prática pedagógica. Justamente porque é também ético considerar as verdades dos outros e outras formas de conhecimentos: - Penso que é válido reforçarmos outras formas de conhecimento, que por mais que não seja aquela que eu comungue, nem por isso tem sua importância diminuída e desrespeitada.

Essa posição de Júlia é semelhante à concepção de Freire (2001, p.79) quando menciona que: 


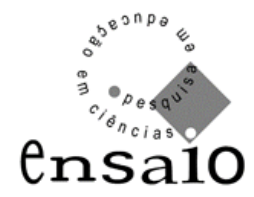

Meu dever ético, enquanto um dos sujeitos de uma prática impossivelmente neutra - a educativa - é exprimir o meu respeito à diferenças de idéias e de posições. Meu respeito até mesmo às posições antagônicas às minhas, que combato com seriedade e paixão.

\section{REFLEXÃO ÉTICO-POLÍTICA NO ENSINO DE CIÊNCIAS: UMA SÍNTESE}

Retomando as questões que nos mobilizaram no desenvolvimento desse percurso investigativo, inferimos a relevância da inserção de discussões epistemológica na formação docente dado seu potencial de desencadear reflexões sobre a necessidade de se construir práticas educativas alicerçada em princípios éticos. Princípios que foram incorporados, pelos professores participantes, à justificação social da educação pela ciência.

Nessa perspectiva, os sujeitos de nossa investigação, ao evocarem as dimensões ética e político por meio das discussões epistemológicas em suas memórias docentes, no que se refere à natureza da ciência e o ensino de ciências, corroboraram com o que já acreditávamos, mas agora pudemos entender de modo ampliado, isto é, há estreita relação entre como se concebe ciência e como se ensina ciência (MALDANER, 2000a, b), pois desvelaram de maneira crítica e dentro do que lhes foi possível, naquele momento de formação, os modos como relacionam suas concepções acerca da produção científica e o ensino que praticam.

Assim, com base nas problematizações acerca da concepção de ciência dogmática neutra, impulsionadas pelas discussões epistemológicas, emergiu a reflexão ético-política no âmbito da prática educativa. A emergência de tal reflexão significou para os sujeitos se admitirem como ativistas políticos no campo da Educação em Ciências e, reconheceram que "embora as acções educacionais dos professores e formadores de professores não possam resolver os problemas sociais e econômicos com que nos deparamos, podem contribuir para construção de sociedades mais justas e mais decentes" (ZEICHNER, 1993, p.65).

A intenção de contribuir para a construção de um mundo melhor parece ter sido re-acionada pelas memórias dos sujeitos. Por meio dessas memórias, os professores participantes puderam rever criticamente seus processos de formação. 


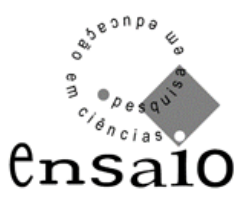

Fizeram relações entre a produção da ciência e sua necessária ancoragem em critérios éticos-políticos de validação, como também submeteram a análise de suas próprias práticas educativas a esses critérios, de tal modo que suas narrativas de formação passaram a apontar necessidade de inclusão de outras concepções de ciência, ensino e educação para serem incorporadas na re-construção de suas identidades docentes.

\section{REFERÊNCIAS BIBLIOGRÁFICAS}

CACHAPUZ, Antônio, et al. A necessária renovação do ensino de ciências. São Paulo: Cortez, 2005.

CACHAPUZ, Antônio; PRAIA, João; JORGE, Manuela. Da educação em ciências às orientações para o ensino das ciências: um repensar epistemológico. Ciência \& Educação, v.10, n.3, p.363-381, 2004.

CHASSOT, Áttico. Alfabetização científica: questões e desafios para a educação. 3. ed. Ijuí: Unijuí, 2003.

CHAVES, Sílvia N. A inserção do debate epistemológico na formação de professores de ciências: caminhos e desafios para a prática docente. Atas do V ENPEC, CDROM, p.1-8, 2005.

COLOMBO, Leonor C.; SALINAS, Julia S. Es importante la epistemología de lãs ciências em la formación de investigadores y professores em física? Ensenânza de las ciencias, v.22, n.3, p.455-462, 2004.

FREIRE, Paulo. Pedagogia da esperança: um reencontro com a pedagogia do oprimido. 8. ed. Rio de Janeiro: Paz e Terra, 2001.

LACEY, Hugh. A ciência e o bem estar humano: para uma nova maneira de estrutura a actividade cientifica. In: Souza Santos, Boaventura de (org.). Conhecimento prudente para uma vida decente: um discurso sobre as ciências revisitado. São Paulo: Cortez, 2004. p.471-493.

MALDANER, Otávio A. A formação inicial e continuada de professores de química professor/pesquisador. Ijuí: UNIJUÍ , RS, 2000a.

Concepções epistemológicas no ensino de ciências. In: Schenetzler, Roseli P.; ARAGÃO, M. R. Rosália.(org.). Ensino de ciências: fundamentos e abordagens. São Paulo: UNIMEP/CAPES, 2000b. p.60-81. 


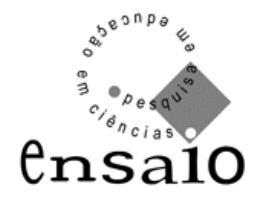

A formação continuada de professores: ensino e pesquisa na escola. Tese (Doutorado) - Faculdade de Educação, Universidade de Campinas, São Paulo, 1997.

MARQUES, Mario Osório. Educação nas ciências: interlocução e complementaridade. Ijuí: Unijuí, 2002.

SANTOS, Wildson Pereira dos; MORTIMER, Eduardo F. Uma análise de pressupostos teóricos da abordagem C-T-S (Ciência- Tecnologia- Sociedade) no contexto da educação brasileira. Ensaio - Pesquisa em Educação em Ciências, v.2, n.2, p.1-23. 2002.

SANTOS, Boaventura de. Um discurso sobre as Ciências na transição para uma ciência pós-moderna. Revista de estudos avançados USP, p.46-71, maio/junho 1988.

ZEICNHER, Kenneth M. A formação reflexiva de professores: idéias e práticas. Lisboa: Educa, 1993.

Data de recebimento: 30/07/08

Data de aprovação: 11/06/09

Data de versão final: 17/07/09 